\title{
On the Cultivation of Civil Engineering English Translators Based on Its Language Features
}

\author{
Yan LI \\ The Engineering and Technical College of Chengdu University of Technology \\ Leshan, 614000, China \\ 295199077@qq.com
}

Keywords: civil engineering English, language features, cultivation, translation

\begin{abstract}
China and cooperation with the oversea construction companies, the demand for the knowledge of civil engineering English (CEE) and translators in this field has been increasing in recent years. This paper aims to analyze the language features of CEE from two aspects-vocabulary and sentence structure, and, based on the analysis, propose to set up a translation workshop and a process appraisal system in a student-centered environment for the cultivation of translation talents of CEE.
\end{abstract}

\section{Introduction}

The development of science and technology stimulates the development of English for Special Purpose (ESP). ESP is a variety of English specially used in a certain field, and mainly to pass the information and knowledge of this field, which, generally, distinguishes itself from general English mainly in vocabulary, syntax, grammar and the layout of the text. And Civil Engineering English (CEE) is a kind of special English used in the field of construction industry. Meanwhile, with the increasing interaction and cooperation with the oversea companies in the international construction projects and the infrastructural projects at home, to know about the language features of CEE comes to be important to all the people in the construction line, including translators, and the demand for translator in CEE has also grown.

Then we will find that on one hand, the translators in CEE falls shout of demand, and on the other hand, there is a great gap between the expectation of the public about the graduates in this line from the universities and their actual translation ability. But the cultivation of translators in CEE is not an easy job. This paper is about to analyze the language features of CEE from vocabulary and syntax in the hope of providing some suggestions for the teaching of CEE.

\section{Language Features}

As we know, CEE is noted for its technical terms and sentence structure. So in the following part, the writer wants to analyze the language features of CEE from the lexical and syntactical aspects.

The Lexical Features. Vocabulary has distinguished features and of great importance in realizing the function of CEE. The vocabulary of CEE can be classified into two types: technical terms and non-technical words.

a. Technical Terms

It is known that we should use some accurate terms to illustrate the natural events or reveal the rules, procedures or skills of the events. These terms are technical terms. Technical terms could be simply taken as terms which can only be applied to some certain text.

The technical terms are very professional and stable, have narrow or solo lexical meaning, and the meanings of the terms would not vary with the usage and culture. Besides, the longer the vocabulary is, the more stable the lexical meaning is. As disciplines go, civil engineering is a branch of speciality, and also, in a sense, is a interdisciplinary subject, for which refers to physics, chemicals, geography, geology, material science, aesthetics and architecture. As a result, most of the technical terms of CEE derivate from the Latin or Greek words. These features make the text of 
CEE contain a lot of words originating from Latin or Greek, such as intrados, spandrel, igneous rock, molten magmas, recrystallization, accessories, bisectrix, axonometric drawing, and so on.

b. Non-technical Words

These words actually derive from the common daily vocabulary, but they are frequently used in disciplines and their meanings are restrained with the context. And due to the influence of society, psychology and cognition and the internal development of language, these common words gradually turn to be technical terms; so sometimes, we call them as semi-technical terms. The technical terms comes from Latin or Greek; but with the intense appearance of new things and concepts, scientists, to vividly illustrate the new things or concepts, try to use common words of known things or concepts to name the new ones based on the similarities between them, such as their similar shapes, functions or usages.

In a CEE text, we usually find that one word is not only applied to one subject, but also applied to many other subjects with different professional meanings, and even one word in a subject has more than one meaning in different contexts. For example, toe in foundation engineering means toe slab, and heel means heel slab. But in "the toe of the H-pile to be protected with cast iron shoes", toe and cast iron shoes refers to the upper and lower protecting devices of H-pile.

Syntactical Features.It is very common in a CEE text that there are two noted characteristics. One is that most of the sentences are in passive voice, while the other is that most of the sentences are long and complicate. The details are as follows:

a. Sentences in Passive Voice

CEE, as a kind of ESP, is mainly to illustrate the essence, appearance, development and changes of the natural events and the internal relationship between objectives. Therefore, most of the sentences are in passive voice to make the text objective and scientific, for if the sentences are in active voice, we would use the first or second person, which is more subjective. And if the sentences have to be in active voice, the subject usually be impersonal and the predicate verbs usually are the varieties of "be", as shown in the following examples:

(1) "The main problem in the design of the foundations of a multi-storey building under which the soil settles is to keep the total settlement of the building within reasonable limits, but specially to see that the relative settlement from one column to the next is not great."

(2) "The loads a structure is subjected to are divided into dead loads, which include the weights of all the parts of the structure, and live loads, which are due to the weights of people, moveable equipment, etc."

b. Long and Complicate Sentence Structure

Although in a CEE text, we usually use a lot of compound words, noun phrases or absolute structure to compress the length of sentences, it is very usual for us to make use of long sentences to express some relative complex concepts or things clearly with a lot of phrases, clauses and conjunctions, such as "before, then, also, furthermore, however, on the contrary, hence, consequent, therefore, etc.", as is shown in the following sentences

(1) "To illustrate with reference to the beam just described, if the short-time peak load had been applied early in the life of the member, before time-depended deformations occurred, the sustained-load deflection§sus of step 3 should be calculated using Ie based on the total load-moment diagram (sustained plus and peak load) because the cracking which would result from that load would permanently reduce the stiffness of the member"

(2) "Based on information supplied by the other specialists, construction management civil engineers estimate quantifies and costs of materials and labor, schedule all work, order materials and equipment for the job, hire contractors and subcontractors, and perform other supervisory work to ensure the projects is completed on time and as specified.”

\section{The Cultivation of Translation Talents}

Based on the analysis of the language features of CEE, here the writer tries to give some teaching suggestions for the cultivation of translators in CEE.

Student-centered Teaching Method.The traditional CEE teaching used to explain translation 
skills during classes, that is, teacher-centered, and the students were deprived of language practices and became passive receivers, which made them lack of interest and initiatives. Thus, it is necessary to change the teaching method to be student-centered, which is interactive and inspiring. For example, the students could work in groups and finish the tasks with the help of group members.

As the above shows, the technical terms with narrow lexical meaning and lack of meaning change are professional and accurate,. What a teacher should do is to ask the students to bear them in mind with the help of group members. The understandings of technical terms would be tested within groups, among groups and by the teacher. By this way, it is a easy job for the students to remember technical terms. If possible in the translation process, the students could just look up the terms online or special dictionaries.

As for the non-technical words, the students should be required to find out this kind of words as many as possible with their own analysis. We know the meaning of this type is changeable and difficult to master. If the teacher just stuffed the students with the knowledge of the words, it would be that the students did not want to remember and easily forgot. On the contrary, if the students do the things by themselves, it is possible that they are interested in the task and easily bear these words in their mind. That is what we say "student-centered".

Concerning the sentences, students should understand the meanings. If possible, the students should be encouraged to translate the sentences, especially, the long and complex sentences. What a teacher should do is give suggestions for the understanding and translation of the sentences, such as translation methods or strategies. Generally, teachers could ask students to find out the structure and main idea, analyze the logical relationships among the elements, and reorganize the meanings of the sentence according to the Chinese thinking way because most of the sentences are in active voice and short, which makes Chinese vivid and lively.

To Set Up a Translation Workshop. Practice makes perfect. As we know, knowledge comes from and is tested in practices. So the translation of CEE actually is a way to test the knowledge and skills of students in CEE. Then, we should set up a translation workshop and make it be the extension of classes to consolidate students' knowledge.

The workshop should focuses on two things-non-technical words and long and complex sentences, for they are very difficult to master and easily be misunderstood. Therefore, for each translation task, the students should be given a lot of practices concerning the two fields. And their translation versions should be checked within and among groups, which could enhance the students' confidence and level of translation.

To Establish A Process Appraisal System. It is necessary to establish a process appraisal system to test the knowledge of students. The traditional evaluation used to be the end appraisal, which means that at the end of courses, the students would be tested and their scores would be their final grades. But due to the language features of CEE, it is impossible for the students to master most of the skills and knowledge of CEE, if the students are only required to pass an exam. Therefore, we should change the current appraisal system to a process appraisal. That is to say, a student' grade would not be the score of an exam, but consists of several evaluation measures, including the students' class attendance and performance, students' attitude, learning procedures, practices, extracurricular activities, tests and exams, etc. in a word, the process appraisal system focuses on the dynamic development of students' knowledge and skills, pays attention to individual differences and take into consideration the student s' attitudes, performance and progress in the whole process.

\section{Conclusion}

As mentioned above, CEE has its own unique language features, mainly represented by lexical and syntactical features. These features make CEE texts concise and accurate with well-knit structures.

For the teaching of CEE, teachers should adopt student-centered teaching method and establish a process appraisal system, which can not only ensure that the students will have enough knowledge and translation skills of CEE, but also provide a lot of tasks for students to practice, which is useful and helpful for them after graduation if they are about to work in civil engineering. If possible, 
meanwhile, the students could ask the experienced translators and experts of CEE for help, which would give them detailed explanations and specific knowledge.

\section{References}

[1]Cabre. T. M. Theories of Terminology: Their Description and Explanation. Terminology, Volume 9, Number 2, 2003: 163-199.

[2]Chen Ying. Civil Engineering English. Beijing: China Machine Press, 2009.

[3]Deng Yousheng. Research on Skills of Translating from Civil Engineering Specialty English into Chinese. Chinese Science \& Technology Translators Journal, 2004 (4):12-13.

[4]Esteban, A. A. \& Canado, M. Making the Case Method Work in Teaching Business English: A Case Study. Journal of English for Specific Purpose, 2004: 137-161.

[5]Huang Jianping \& Deng Liang. Formation Mechanism of EST Terms and E/C Translation Strategies : A Case Study of Civil Engineering English. Foreign Language Literature, 2012 (6): 129-131.

[6]Jackson, J. Reality-based Decision Cases in ESP Teacher Education: Windows on Practice. Journal of English for Specific Purposes. 1998, 151-167.

[7]Liu Guilan \& Shao Juanping. An Inquiry into the Quality Education to the Cultivation if Engineering English Translation Talents. Journal of Hubei TV University, 2011 (1): 106-107.

[8]Xia Tangdai. Construction and Engineering English. Wuhan: Huazhong University of Science and Technology Press, 2005.

[9]Zhang Dongmei. On the English Translation of Chinese Tender Documents. [J] Chinese Science \& Technology Translators Journal, 2006 (3): 11-13. 